\title{
Shelf-life of reduced-fat white chocolate fillings using iota-carrageenan
}

\author{
João Dias ${ }^{1 *}$, Nuno Alvarenga ${ }^{1,2,3}$, Isabel Sousa ${ }^{2,4}$ \\ ${ }^{1}$ Polytechnic Institute of Beja, Rua Pedro Soares, 7800-295 Beja, Portugal, ${ }^{2}$ LEAF, Instituto Superior de Agronomia, Universidade de Lisboa, \\ Tapada da Ajuda, 1349-017 Lisbon, Portugal, ${ }^{3}$ GeoBioTec Research Institute, Universidade Nova de Lisboa, Campus de Caparica, $2829-516$ \\ Caparica, Portugal, ${ }^{4}$ DCEB, Instituto Superior de Agronomia, Universidade de Lisboa, Tapada da Ajuda, 1349-017 Lisbon, Portugal
}

\section{A B S T R A C T}

\begin{abstract}
The conservation of traditional chocolate fillings can present some hurdles due to the use of perishable raw matters, physical changes during processing and to the influence of external factors, which tends to shorten shelf-life of traditional filled pralinés to only 3-4 months. The aim of this study was to evaluate the influence of the concentration of iota-carrageenan on chemical, rheological, image analysis and microbial properties of reduced-fat white chocolate fillings during storage time. Two batches of reduced-fat filling were produced using white chocolate, commercial grade sugar, skimmed milk, inverted sugar and iota-carrageenan (at $0.5 \% \mathrm{w} / \mathrm{w}$ and $1.0 \% \mathrm{w} / \mathrm{w}$ concentration) and stored at $4{ }^{\circ} \mathrm{C}$ during 12 months. A control batch with no hydrocolloid was also produced. The results presented a decrease in $\mathrm{pH}$, $\mathrm{a}_{\mathrm{w}}$ and moisture during storage time. The rheological characterization concluded that all formulations presented a shearthinning behaviour and both flow index $(\mathrm{n})$ and consistency $(\mathrm{K})$ were correlated with iota-carrageenan concentration and with storage time. The concentration of iota-carrageenan did not influence the digital image analysis of chocolate fillings, but a shift was observed during storage time, especially at the end. The microbial analysis showed a positive correlation to storage time in the formulation using $1.0 \%$ iota-carrageenan, nevertheless all results were quite acceptable and within the recommended safety values.
\end{abstract}

Keywords: Chocolate; Reduced-fat; lota-carrageenan; Shelf-life

\section{INTRODUCTION}

The storage of handmade pralines can present some shelflife limitations due to the use of sensible ingredients, changes during manipulation and processing and environmental conditions. These factors together are the responsables for the short shelf-life of handmade filled chocolates, around 3-4 months, limiting its commercialization. In the present literature, the results show shelf-lives of low-caloric fillings around 2-3 months (Afonso, 2007) and 2-3 months in conventional fillings (Pires, 2007; Wybauw, 2007). The main factors affecting shelf-life of filled chocolates are (1) physical properties: drying, loss of flavour, absortion of external flavours, fat separation, sugar bloom and fat bloom; (2) microbiological stability: due to the incorporation of ingredients with high moisture like cream, butter and fruit purée; (3) chemical properties: like oxidation/hidrolysis of fatty acids (Wybauw, 2004).
The short term solutions to reduce spoilage risk include the thermal treatment of cream, including boiling, pasteurization or sterilization (Wybauw, 2004). Nevertheless, thermal treatments present an high risk of loss of flavour or the development of odd-flavours like caramel or burnt. A longer shelf-life period for filled pralines will require redution of water activity $\left(\mathrm{a}_{\mathrm{w}}\right)$, redution of $\mathrm{pH}$, use of ethanol, use of preservatives (Marvig et al., 2014) or storage at low temperatures (Wybauw, 2010). Nevertheless, the safety of filled chocolates can be affected by like osmophilic yeasts, xerophilic moulds and bacteria that tolerate low a $\mathrm{w}_{\mathrm{w}}$ (Marvig et al., 2014).

The aim of this study was the evaluation of the influence of iota-carrageenan concentration on chemical, rheological, image analysis and microbial properties of reducedfat white chocolate fillings and the evolution of these parameters during storage. This was motivated by the

\footnotetext{
${ }^{*}$ Corresponding author:

João Dias. Polytechnic Institute of Beja, Rua Pedro Soares, 7800-295 Beja, Portugal, Tel. +351284314 300; Fax. +351284 388207.

E-mail address: joao.dias@ipbeja.pt

Received: 08 May 2017; Revised: 17 November 2017; Accepted: 19 November 2017; Published Online: 28 November 2017
} 
fact that the reduced-fat formulations in chocolate fillings appear to not have been studied extensively, or, at least, limited information is available in the open literature.

\section{MATERIALS AND METHODS}

\section{Materials}

Filled chocolates with reduced-fat filling were produced by the authors in a local confectionery (Sugar Bloom, Beja, Portugal) using tempered dark chocolate $51 \%$ cocoa for couverture (CHD-R515-565, Sicao, Wieze, Belgium) at $29.5^{\circ} \mathrm{C}$. Two batches of reduced-fat filling were produced using white chocolate (CDW-U2630-557, Sicao, Wieze, Belgium), commercial grade sugar, skimmed milk $(0.3 \%$ $\mathrm{w} / \mathrm{w}$ fat content), inverted sugar (Trimoline $81 \%$ dry extract, DGF, Chanteloup-les-vignes, France) and iotacarrageenan (Sosa Ingredients, Barcelona, Spain) at $0.5 \%$ $\mathrm{w} / \mathrm{w}$ and $1.0 \% \mathrm{w} / \mathrm{w}$ concentration. A control batch with no hydrocolloid was also produced.

\section{Technological methods}

The preparation of reduced-fat fillings included the mixture of skimmed milk, iota-carrageenan, inverted sugar and commercial sugar, according to Dias et al. (2015). The formulations are presented in Table 1 . After demoulding, the filled chocolates were kept at $25{ }^{\circ} \mathrm{C}$ for $24 \mathrm{~h}$ to fully cristallize the cocoa butter, packed in cardboard boxes, stored at $4{ }^{\circ} \mathrm{C}$ and analysed at 0,6 and 12 months of storage time.

\section{Chemical analysis}

The moisture content, $\mathrm{a}_{\mathrm{w}}$ and $\mathrm{pH}$ were performed in quintuplicate $(n=5)$, according to Dias et al. (2017).

\section{Rheological tests}

A rotational viscosimeter VT 550 (ThermoHaake, Karlsruhe, Germany) was used to perform the rheological measurements at $20 \pm 1^{\circ} \mathrm{C}$. The geometries used were coneand-plate (PK1 $1^{\circ}$ diameter $10 \mathrm{~mm}$ and PK5 $1^{\circ}$ diameter $50 \mathrm{~mm}$ ) and the interval of shear rate was $10^{1}-10^{3} \mathrm{~s}^{-1}$. The rheological essays were led in quintuplicate $(n=5)$.

Table 1: Formulations of reduced-fat fillings

\begin{tabular}{|c|c|c|}
\hline Control & $\begin{array}{l}\text { Hydrocolloid } \\
0.5 \% \mathrm{w} / \mathrm{w}\end{array}$ & $\begin{array}{l}\text { Hydrocolloid } \\
1.0 \% \mathrm{w} / \mathrm{w}\end{array}$ \\
\hline $45.0 \%$ skimmed milk & $\begin{array}{l}44.5 \% \text { skimmed } \\
\text { milk }\end{array}$ & $\begin{array}{l}44.0 \% \text { skimmed } \\
\text { milk }\end{array}$ \\
\hline $22.0 \%$ sugar & $22.0 \%$ sugar & $22.0 \%$ sugar \\
\hline $\begin{array}{l}11.0 \% \text { inverted } \\
\text { sugar }\end{array}$ & $\begin{array}{l}11.0 \% \text { inverted } \\
\text { sugar }\end{array}$ & $\begin{array}{l}11.0 \% \text { inverted } \\
\text { sugar }\end{array}$ \\
\hline \multirow[t]{2}{*}{$\begin{array}{l}22.0 \% \text { white } \\
\text { chocolate }\end{array}$} & $\begin{array}{l}22.0 \% \text { white } \\
\text { chocolate }\end{array}$ & $\begin{array}{l}22.0 \% \text { white } \\
\text { chocolate }\end{array}$ \\
\hline & $\begin{array}{l}0.5 \% \\
\text { iota-carrageenan }\end{array}$ & $\begin{array}{l}1.0 \% \\
\text { iota-carrageenan }\end{array}$ \\
\hline
\end{tabular}

The Ostwald model (simplified in power law) was used in order to assess theflow curves obtained was (Glicerina et al. 2013; Dias et al. 2015). This model is represented in the following equation:

$$
\tau=K \cdot \dot{\gamma}^{n}
$$

where $\tau$ is the shear stress $(\mathrm{Pa}), K$ is consistency index $\left(\mathrm{Pa} . \mathrm{s}^{\mathrm{n}}\right)$, is the shear rate $\left(\mathrm{s}^{-1}\right)$ and $n$ is the dimensionless flow behaviour index.

\section{Digital image analysis}

Image analysis procedure was based on literature (Briones and Aguilera, 2005; Briones et al., 2006; Nopens et al., 2008; Stoops, 2011). Image analysis was conducted in quintuplicate $(n=5)$ according to Dias et al. (2015). The first step was the extration of the Region Of Interest (ROI) of each image, corresponding to the cross section of the filling (Fig. 1) and the surface of couverture chocolate (Fig. 2).

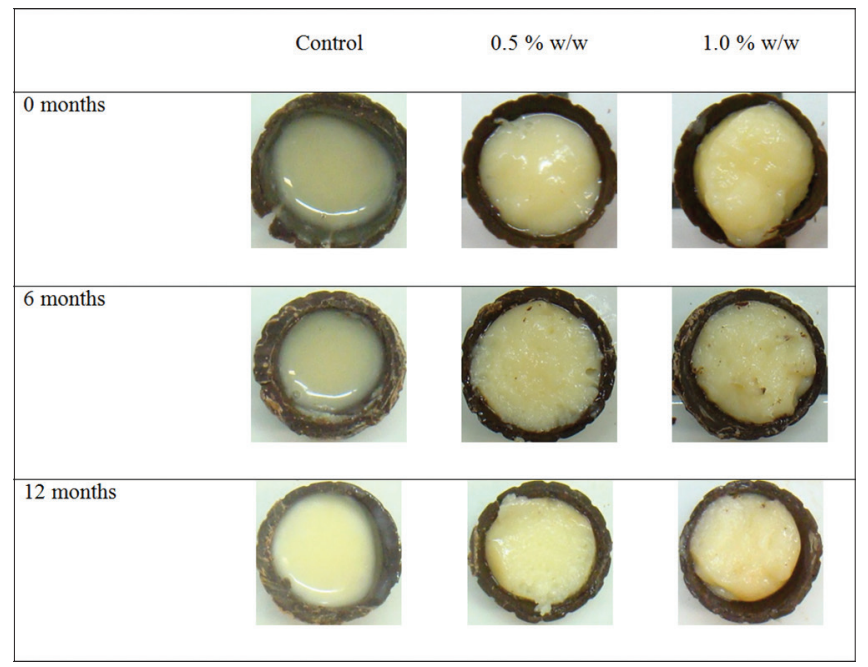

Fig 1. Digital image of chocolate fillings.

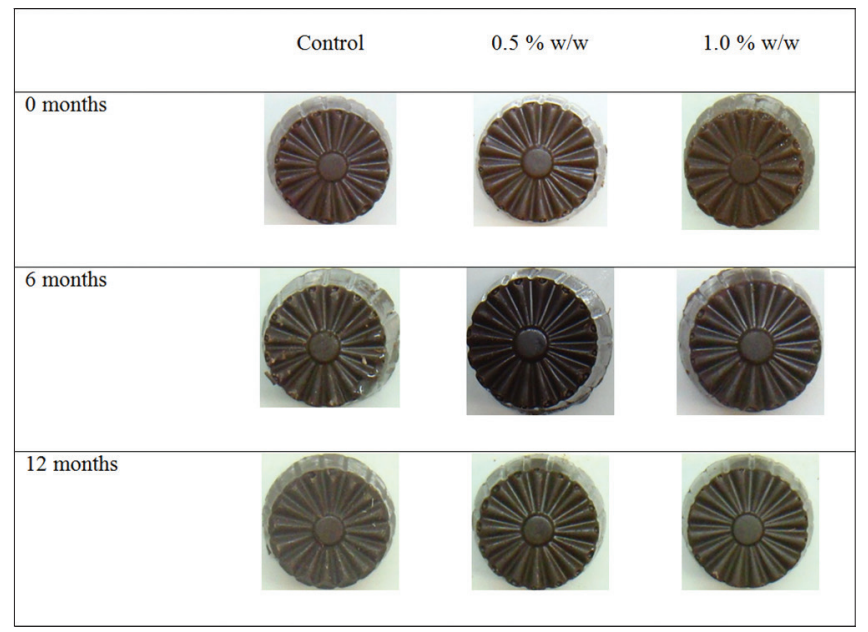

Fig 2. Digital image of chocolate couvertures. 


\section{Microbiological analysis}

Samples of the chocolate fillers (12 g) were diluted according to Dias et al. (2015). The media for total aerobic mesophiles viable organisms was Plate Count Agar CM0325 (Oxoid, Hampshire, UK), incubated at $30^{\circ} \mathrm{C}$ for $72 \mathrm{~h}$. The media for moulds and yeasts was Rose-Bengal Chloramphenicol Agar Base CM0549 (Oxoid, Hampshire, $\mathrm{UK}$ ), incubated at $25^{\circ} \mathrm{C}$. Microbiological analysis was conducted in duplicate $(n=2)$.

\section{Statistical analysis}

The average, standard deviation and 0.95 confidence interval values were determined. Experimental data were subjected to one-way ANOVA (pairwise comparison of means with Scheffé test) in order to find differences during storage time and with the concentration of hydrocolloid. Data was analyzed using a statistic software as in Alvarenga et al. (2011).

\section{RESULTS AND DISCUSSION}

\section{Chemical parameters during storage}

The inital values of moisture content of the filling were similar in all formulations (control, $0.5 \%$ and $1.0 \% \mathrm{w} / \mathrm{w}$ ), between 41 and $44 \%$ (Fig. 3a). Nevertheless, a significant loss was observed during storage time, especially in control samples $(\mathrm{p} \leq 0.05)$. The formulations using iota-carrageenan also presented a moisture loss, especially in the first 6 months period ( $\mathrm{p} \leq 0.05)$. The higher values of moisture in the formulations using iota-carrageenan, compared with control, may be due to its high-water binding ability (Blakemore and Harpell, 2010).

However, the observed moisture loss of the filling did not cause a visible swelling on the surface of the chocolate, as reported in other studies (Svanberg et al., 2012), probably due to the lower storage temperature and different chemical composition.
The fillings of pralines presented initial $\mathrm{a}_{\mathrm{w}}$ values between $0.89(1.0 \% \mathrm{w} / \mathrm{w})$ and $0.93(0.5 \% \mathrm{w} / \mathrm{w})$, higher than other studies in pralines (Marvig et al., 2014), probably due to the higher content of cream (Fig 3b). During storage time, the values of $\mathrm{a}_{\mathrm{w}}$ decreased in all conditions and the final values ranged between $0.72(0.5 \% \mathrm{w} / \mathrm{w})$ and 0.77 (control and $1.0 \% \mathrm{w} / \mathrm{w}$ ), as a direct consequence of the decrease of moisture content (Fig. 3b). These results are supported by one-way ANOVA Scheffè test, where no influence of iotacarrageenan concentration on $\mathrm{a}_{\mathrm{w}}$ was observed $(\mathrm{p}>0.05$, data not shown).

The initial $\mathrm{pH}$ values were around 6.0. A slight decrease on $\mathrm{pH}$ values was observed in the formulations using iota-carrageenan, especially after 12 months storage time (Fig. 4). No significant differences were observed between concentrations of $0.5 \%$ and $1.0 \%$ iota-carrageenan.

\section{Rheological parameters during storage}

The rheological approach of the chocolate fillings included the evaluation of flow index (n) and consistency $(\mathrm{K})$ during storage time. The rheological characterization concluded that all conditions presented a shearthinning behavior $(n<1)$ and negative correlation with storage time, with higher values in control filling. Initially, control formulation presented a rheological behaviour close to a Newtonian fluid ( $\mathrm{n} \sim 0.88$ ) but during storage time and, as a consequence of moisture loss, the behaviour became similar to the formulations using iota-carrageenan (Fig. 5a).

The consistency $(\mathrm{K})$ of the fillings showed a dependency on both storage time and iota-carrageenan concentration $(p \leq 0.05)$. Both $0.5 \%$ and $1.0 \%$ iota-carrageenan presented positive correlation with storage time, possibly as a consequence of the redution of moisture content, affecting the perception of the texture. By the other hand, and as expected, the consistency increased with the concentration of iota-carrageenan (Fig. 5b). This effect can be due to the presence of $\mathrm{Ca}^{2+}$, which contributed to "egg-

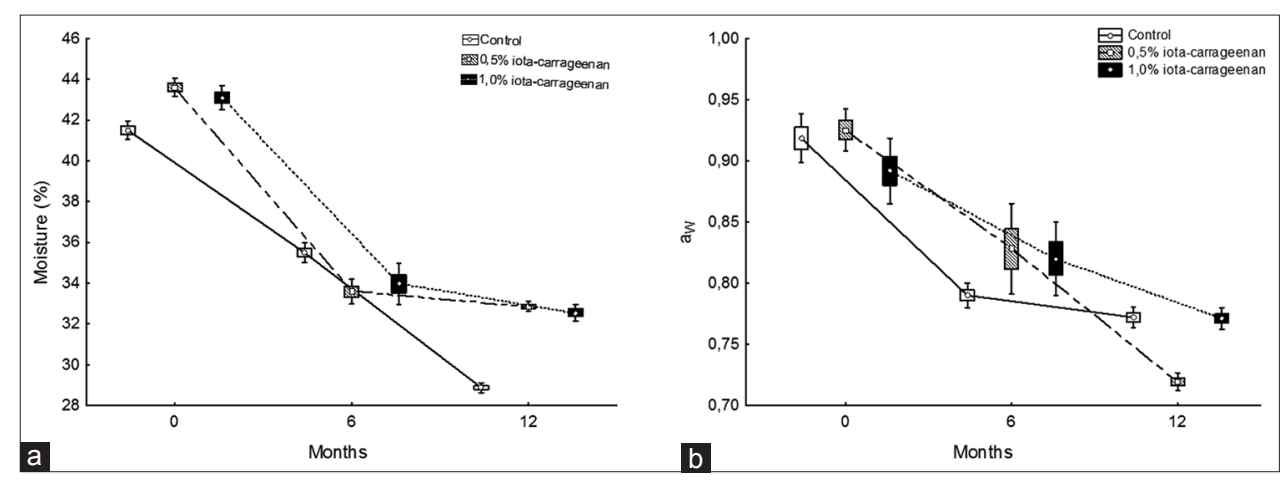

Fig 3. Evolution of moisture (a) and $\mathrm{a}_{\mathrm{w}}$ (b) contentz during storage in control (white), filled chocolate with $0.5 \%$ w/w iota-carrageenan (grey) and filled chocolate with $1.0 \% \mathrm{w} / \mathrm{w}$ iota-carrageenan (black). 
box model" when using iota-carrageenan (Helgerud et al., 2010; Blakemore and Harpell, 2010, Yanes et al., 2002a).

\section{Image analysis during storage}

The digital image analysis of the filling using iotacarrageenan presented initial values between 177 (control) to $182(0.5 \% \mathrm{w} / \mathrm{w})$. A positive correlation with storage time was observed in the formulations using iota-carrageenan, but by the other side, control sample presented a negative correlation with storage time (Fig. 6a). The percentage of iota-carrageenan in the filling presented no significant influence.

The digital image analysis of couverture chocolate (Fig. 6b) presented initial values from 73 (control) to $76(0.5 \% \mathrm{w} / \mathrm{w}$ and $1.0 \% \mathrm{w} / \mathrm{w}$ ), typical values of dark chocolate (Dias et al., 2015). Due to the low storage temperature, it was not observed a colour shift as presented in the literature (Nopens et al., 2008; Briones and Aguilera, 2005) as a result of the polymorphic change of cocoa butter. By the other hand, no major differences were observed in the chocolate couverture as a result of iota-carrageenan concentration, concluding that both $0.5 \%$ and $1.0 \%$ present strong gels with large water retaining properties. The percentage of

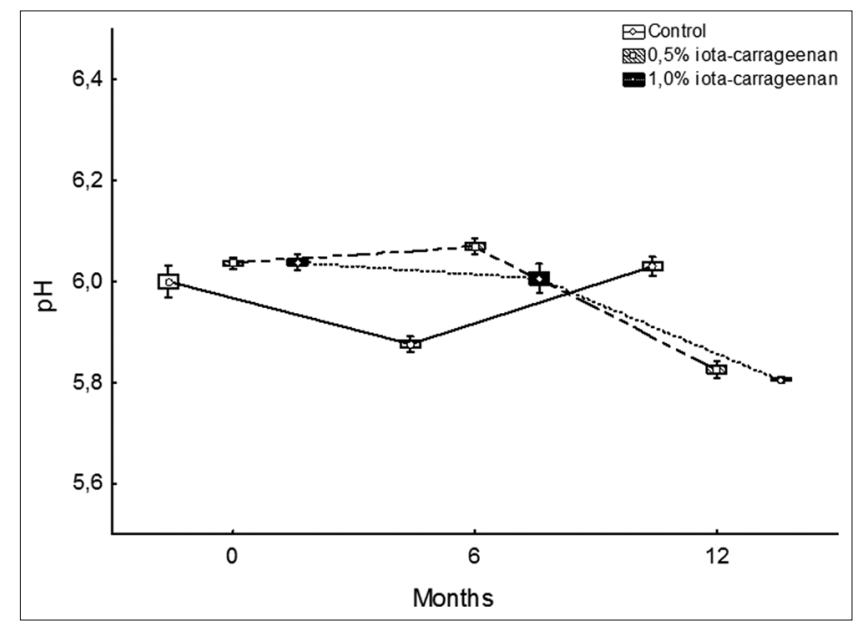

Fig 4. Evolution of $\mathrm{pH}$ during storage. iota-carrageenan in the couverture presented no significant influence (Fig. 6b).

\section{Microbiological flora during storage}

Both moulds and yeasts and total aerobic mesophiles presented low values after production, below $2.0 \times 10^{1}$ $\mathrm{ufc} / \mathrm{g}$ and $1.3 \times 10^{2} \mathrm{cfu} / \mathrm{g}$ respectively (Fig. 7). The results of total aerobic mesophiles in the fillings produced with $0.5 \%$ iota-carrageenan presented negative correlation with storage time, but a positive correlation was observed in the fillings with $1.0 \%$ iota-carrageenan (Fig. 7a). As in other studies, it is not possible to establish a general correlation between $\mathrm{a}_{\mathrm{w}}$ and microbial load, which means that the praline composition alone cannot be connected to the level of spoilage organisms present in the samples (Marvig et al., 2014). Although the results obtained at the end of storage time were quite acceptable in this kind of food product (below $2.5 \times 10^{2} \mathrm{cfu} / \mathrm{g}$ ), the use of hydrocolloid may present itself as a possible contamination source if no additional heat-treatment processes are adopted. In fact, increasing the concentration of iota-carrageenan in the filling contributed to a higher load on total mesophiles, compared with control filling (Fig. 7a). In a previous study, De Clerq et al. (2015) observed that xerophilic fungi are amongst the most potential spoilage organisms present in chocolate fillings, especially the genera Penicillium, Aspergillus, Eurotium and Zygosaccharomyces (Marvig et al., 2014). These organisms were observed in the environment of chocolate factories but mostly in some ingredients used to produce chocolate fillings, like nuts (De Clerq et al., 2015) and sugar syrup (Marvig et al., 2014). In this study, the results of moulds and yeasts during storage time were negligible (Fig. $7 \mathrm{~b}$ ).

\section{CONCLUSIONS}

Two batches of reduced-fat white chocolate fillings were produced, comparing two different concentration of iotacarrageenan and monitoring properties during storage time. The characterization of fillings included chemical, rheological, digital image and microbial evaluation. The

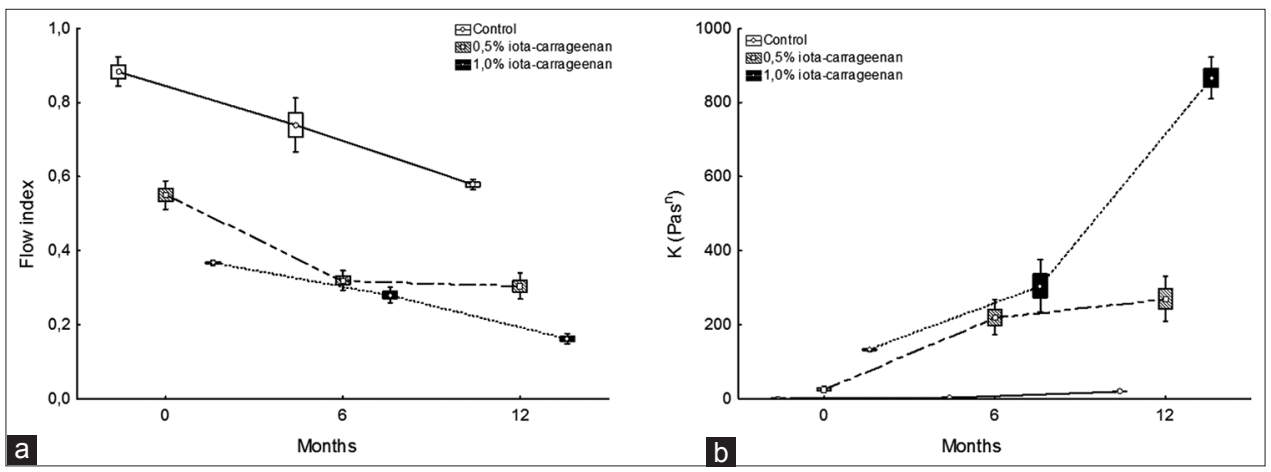

Fig 5. Evolution of flow index (a) and consistency (b) during storage. 


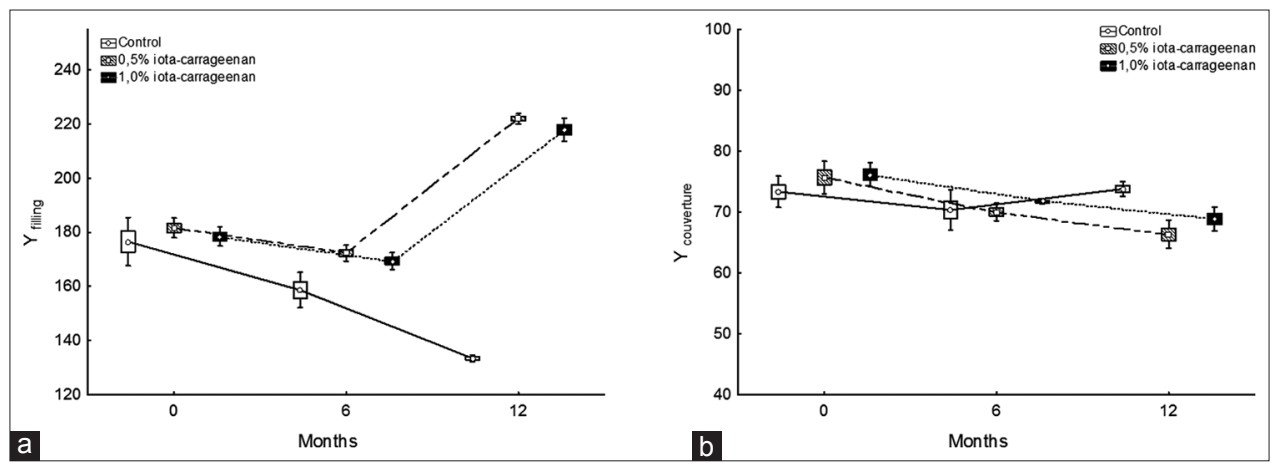

Fig 6. Evolution of filling (a) and couverture (b) luminance during storage.

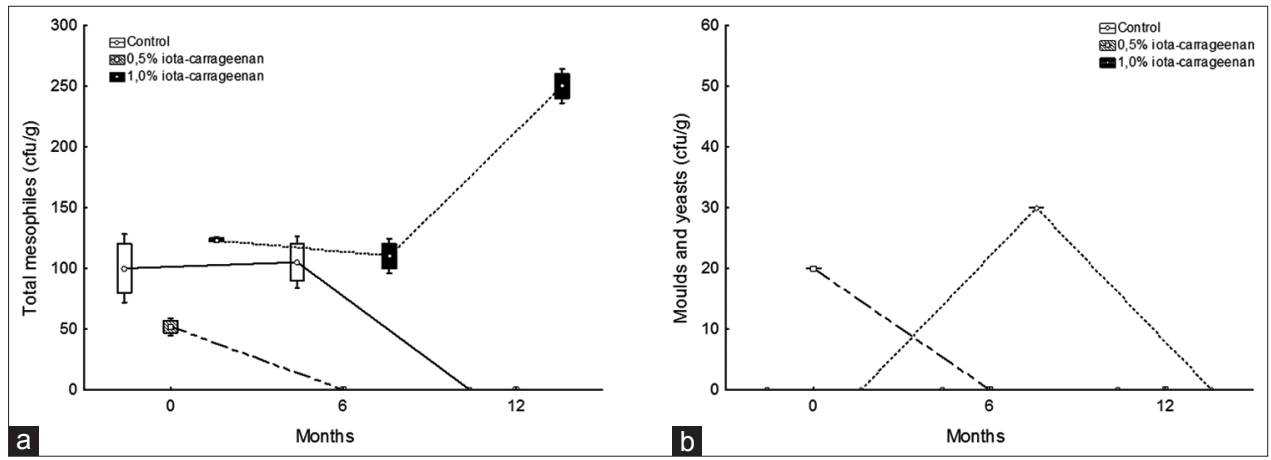

Fig 7. Evolution of total mesophiles (a) and moulds and yeasts (b) during storage.

use of iota-carrageenan in reduced-fat fillings presented a decrease in $\mathrm{pH}, \mathrm{a}_{\mathrm{w}}$ and moisture during storage time. The rheological characterization concluded that all formulations presented a shearthinning behavior $(n<1)$ and both parameters n-flow behavior and $\mathrm{K}$-consistency index were correlated with iota-carrageenan concentration and storage time, probably due to moisture loss. The concentration of iota-carrageenan presented no influence on the digital image analysis of couverture but presented a positive correlation with storage time. The microbial analysis presented a positive correlation to storage time in the formulation using $1.0 \%$ iota-carrageenan but presented a negative correlation using $0.5 \%$ iota-carrageenan, nevertheless all results were quite acceptable in this kind of product. These results conclude that it was possible to produce reducedfat chocolate fillings using iota-carrageenan, with similar properties compared to the control batch. Additionally, it was also observed that the long-term storage time is possible at $4{ }^{\circ} \mathrm{C}$, mantaining most of the original properties and presenting high strandards in food safety.

\section{ACKNOWLEDGMENTS}

The authors are grateful to Azelis Portugal, for the valuable help in providing the hydrocolloids, and to Mestre Cacau / Sugar Bloom for providing the chocolate and facilities for the production of the samples. The authors are also thankful to Fundação para a Ciência e Tecnologia for the grant PROTEC to João Jorge Mestre Dias under his PhD thesis.

\section{Authors' contributions}

João M. Dias: involved in the physical, chemical and microbiological analysis and writing of the paper. Nuno B. Alvarenga: inovolved in rheological analysis, statistical analysis and writing of the paper. Isabel Sousa: involved in the overall planning, supervision of the work.

\section{REFERENCES}

Afonso, C. 2007. Development of Low-caloric Filled Chocolates (In Portuguese). M.Sc. Dissertation, Technical University of Lisbon, Lisbon.

Alvarenga, N., J. Canada and I. Sousa. 2011. Effect of freezing on the rheological, chemical and colour properties of serpa cheese. J. Dairy Res. 78: 80-87.

Blakemore, W. and A. Harpell. 2010. 5 Carrageenan. In: Imeson, A., editor. Food Stabilisers. Thickeners and Gelling Agents, WileyBlackwell, Oxford. pp. 73-94.

Briones, V. and J. Aguilera (2005). Image analysis of change in surface color of chocolate. Food Res. Int. 38: 87-94.

Briones, V., J. Aguilera and C. Brown. 2006. Effect of surface topography on color and gloss of chocolate samples. J. Food Eng. 77: 776-783.

De Clerq N., E. Van Coillie, E. Van Pamel, B. De Meulenaer, F. Devlieghere and G. Vlaemynck. 2015. Detection and 
identification of xerophilic fungi in belgian chocolate confectionery factories. Food Microbiol. 46: 322-328.

Dias, J., N. Alvarenga and I. Sousa. 2015. Effect of hydrocolloids on low-fat chocolate fillings. J. Food Sci. Technol. 52: 7209-7218.

Dias, J., P. Coelho, N. Alvarenga, R. Duarte and J. Saraiva. 2017. Evaluation of the impact of high pressure on the storage of filled traditional chocolates. Innov. Food Sci. Emerg. Techno. 45: 36-41.

Glicerina, V., F. Balestra, M. Rosa and S. Romani. 2013. Rheological. textural and calorimetric modifications of dark chocolate during process. J. Food Eng. 119: 173-179.

Marvig, C., R. Kristiansen, M. Madsen and D. Nielsen. 2014. Identification and characterisation of organisms associated with chocolate pralines and sugar syrups used for their production. Int. J. Food Microb. 185: 167-176.

Nopens, I., I. Foubert, V. De Graef, D. Van Laere, K. Dewettinck and P. Vanrolleghem. 2008. Automated image analysis tool for migration fat bloom evaluation of chocolate coated food products. LWT. 41: 1884-1891.
Pires, R. 2007. Shelf-life Study of Handmade Filled Chocolates (in portuguese). Bachelor Dissertation, Technical University of Lisbon, Lisbon.

Stoops, K. 2011. Evaluation of Storage Temperature on Quality Parameters of Dark Chocolate: Effect of Fat and Xanthan Gum (in dutch). M.Sc. Dissertation, Katholieke Hogeschool Kempen, Geel.

Svanberg, L., N. Lorén and L. Ahrné. 2012. Chocolate swelling during storage caused by fat or moisture migration. J. Food Sci. 77(11): E328-E334.

Wybauw, J. 2004. Fine Chocolates - Great Experience. Lannoo Publishing, Tielt.

Wybauw, J. 2007. Fine Chocolates - Great Ganache Experience 2. Lannoo Publishing, Tielt.

Wybauw, J. 2010. Fine chocolates - Great experience 3. Extending Shelf Life. Lannoo Publishin, Tielt.

Yanes, M., L. Durán and E. Costell. 2002. Effect of hydrocolloid type and concentration on flow behaviour and sensory properties of milk beverages model systems. Food Hydrocoll. 16: 605-611. 